\title{
Paroxysmal positional vertigo despite complete vestibular impairment: the role of instrumental assessment
}

\author{
Vertigine parossistica posizionale benigna dopo deficit vestibolare totale: quale \\ ruolo per la valutazione otoneurologica strumentale? \\ A.P. CASANI, N. CERCHIAI, E. NAVARI \\ Department of Medical and Surgical Pathology, Otorhinolaryngology Section, Pisa University Hospital, Pisa, Italy
}

\section{SUMMARY}

Lindsay-Hemenway syndrome is characterised by a posterior canal benign paroxysmal positional vertigo following a partial unilateral vestibular loss affecting the same side. The syndrome is caused by damage of structures innervated by the superior division of the vestibular nerve and perfused by the anterior vestibular artery; the detached otoconia can cause vertigo in the still intact posterior semicircular canal. The most recent vestibular instrumental techniques allow reaching an accurate topodiagnosis in case of peripheral vestibular failure. We report on two cases of Lindsay-Hemenway syndrome despite complete vestibular failure demonstrated by vestibular instrumental assessment. After making some critical considerations on these findings, we underline the importance of not disregarding the diagnosis of paroxysmal positional vertigo in an established complete labyrinthine loss of function.

KEY WORDS: Unilateral vestibular loss • Vestibular evoked myogenic potentials (VEMPs) • video Head Impulse Test (vHIT) • Benign paroxysmal positional vertigo $\bullet$ Lindsay-Hemenway syndrome

\section{RIASSUNTO}

La sindrome di Lindsay-Hemenway si caratterizza per la comparsa di una sindrome vertiginosa acuta da deficit periferico monolaterale seguita da una forma recidivante di vertigine parossistica posizionale ipsilaterale da canalolitiasi del canale semicircolare posteriore. Questo quadro clinico è ricondotto ad una distruzione labirintica parziale e limitata alle sole strutture labirintiche innervate dalla branca superiore del nervo vestibolare e irrorate dall'arteria vestibolare anteriore; gli otoconi degenerati in conseguenza del danno darebbero successivamente luogo alla vertigine posizionale poiché il canale semicircolare posteriore sarebbe risparmiato. Le metodiche strumentali attualmente disponibili nella pratica clinica otoneurologica consentono di delineare una topodiagnosi in caso di deficit vestibolare acuto, identificando le strutture non funzionanti. Di recente sono giunti alla nostra osservazione due pazienti che hanno sviluppato una sindrome di Lindsay-Hemenway sebbene le metodiche strumentali avessero permesso di diagnosticare un danno labirintico completo. Provvederemo ad affrontare criticamente quanto rilevato sottolineando la necessità di non escludere una forma di litiasi conseguente ad un deficit vestibolare anche laddove venga rilevato un danno strumentale completo.

PAROLE CHIAVE: Deficit vestibolare unilaterale • Potenziali evocati vestibolari miogeni (VEMPs) • video Head Impulse Test (vHIT) • Vertigine parossistica posizionale benigna $\bullet$ Sindrome di Lindsay-Hemenway

Cite this article as: Acta Otorhinolaryngol Ital 2018;38:563-568. http://dx.doi.org/10.14639/0392-100X-1549

(C) Società Italiana di Otorinolaringoiatria e Chirurgia Cervico-Facciale

\section{Introduction}

Lindsay and Hemenway ${ }^{1}$ first described an episode of posterior canal benign paroxysmal positional vertigo (PCBPPV) following labyrinthine ischaemic injury. They hypothesised selective damage of the vestibular structures perfused by the anterior vestibular artery, which provides the blood supply to most of the utricle, the superior and horizontal ampullae and to a small portion of the saccule, with consequent detachment of otoconia from the utricle. The otoconia could have then entered into an intact PC causing PPV. Later, Shucknecht and Kitamura ${ }^{2}$ assumed selective viral damage of the superior vestibular nerve $(\mathrm{VN})$ was the cause of the syndrome, by innervating the horizontal (HC) and anterior semicircular canal (AC), the utricle and the anterosuperior part of the saccule. The particular susceptibility to injury of the superior division of the $\mathrm{VN}$ is explained by a selective tropism to some viral agents or by anatomical 
peculiarities of the bone auditory channel; histopathology studies of the temporal bone have shown frequent sparing of the $\mathrm{PC}^{3}$ supporting these findings. Observing a PC-PPV after unilateral vestibular loss (UVL) implies preservation of the structures innervated by the inferior branch of the $\mathrm{VN}^{4}$. Nowadays, the results of ocular vestibular evoked myogenic potentials (O-VEMPs) and cervical vestibular evoked myogenic potentials (C-VEMPs) can be combined with the results of tests, such as the video head impulse test (vHIT), in order to obtain information about the state of the peripheral vestibular function of each sensory organ as well of each branch of the $\mathrm{VN}^{5-7}$. As Morofushi et al. reported in $1996^{8}$, if C-VEMPs are absent from an ear that has suffered acute UVL, PC-PPV is unlikely to develop as a consequence of the UVL because the absence of C-VEMPs imply damage to the structures innervated by the inferior $\mathrm{VN}$ (or of the inferior VN itself). In our ENT Unit, we have recently seen two patients presenting a PC-PPV at 8-14 days after superior and inferior vestibular neurolabyrinthitis, previously identified through an instrumental assessment. We present these cases of PC-PPV after a complete UVL because to our knowledge similar findings have not been described, which underline the necessity to consider a PC-PPV and to perform close follow-up after UVL even if a compete impairment of vestibular sense organs is identified.

\section{Case series}

A 67-year-old woman presented to our Neurotology Service (ENT Unit, Pisa University Hospital) for a standard followup examination 8 days after discharge for a right UVL. During hospital admission a complete clinical and instrumental vestibular assessment was performed. The caloric vestibular test $(\mathrm{CVT})$ revealed a complete canal paresis $(\mathrm{CP})$ on the

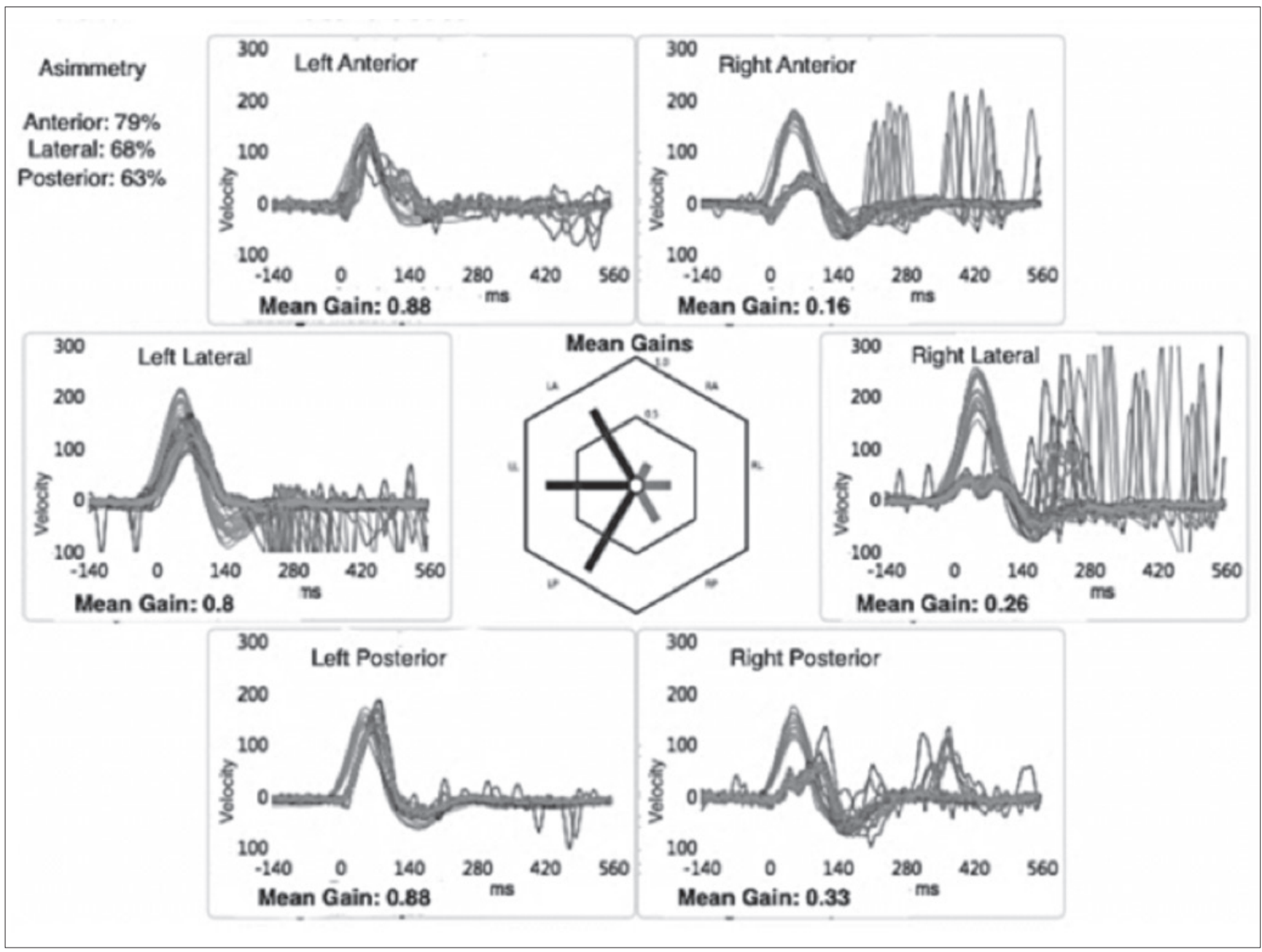

Fig. 1. Case 1, video head impulse test performed by employing a dedicated device ("ICS Impulse" system; GN Otometrics, http://www.icsimpulse.com). Right lateral canal, anterior canal and posterior canal gain are very low $(0.26,0.16,0.33$ respectively). 
right side. vHIT showed a reduction in vestibulo-ocular reflex (VOR) gain values calculated on all the canals of the right side: 0.15 for $\mathrm{HC}, 0.28$ for PC and 0.27 for AC (Fig. 1). Air conducted tone burst (TB) $500 \mathrm{~Hz}$ C-VEMPs were absent on the right sternocleidomastoid muscle (Fig. 2A). Both a bone conducted $500 \mathrm{~Hz}$ STB stimulus at the midline forehead (Fz point) and a $500 \mathrm{~Hz}$ air conducted STB showed no response in the contralesional eye (O-VEMPs) (Fig. 2B). At the follow-up visit she described sudden onset and short-term spinning dizziness upon bending down and getting up, in addition to a mild sensation of unsteadiness. Clinical examination revealed the following: no spontaneous nystagmus, left-beating head-shaking and vibrationinduced nystagmus and a torsional with anti-clockwise direction-up-beating nystagmus in right Dix-Hallpike positioning. The paroxysmus and the fatigability of this positional nystagmus, associated with the inversion of its direction when returning the patient to a sitting position, allowed us to make diagnosis of PC-PPV.

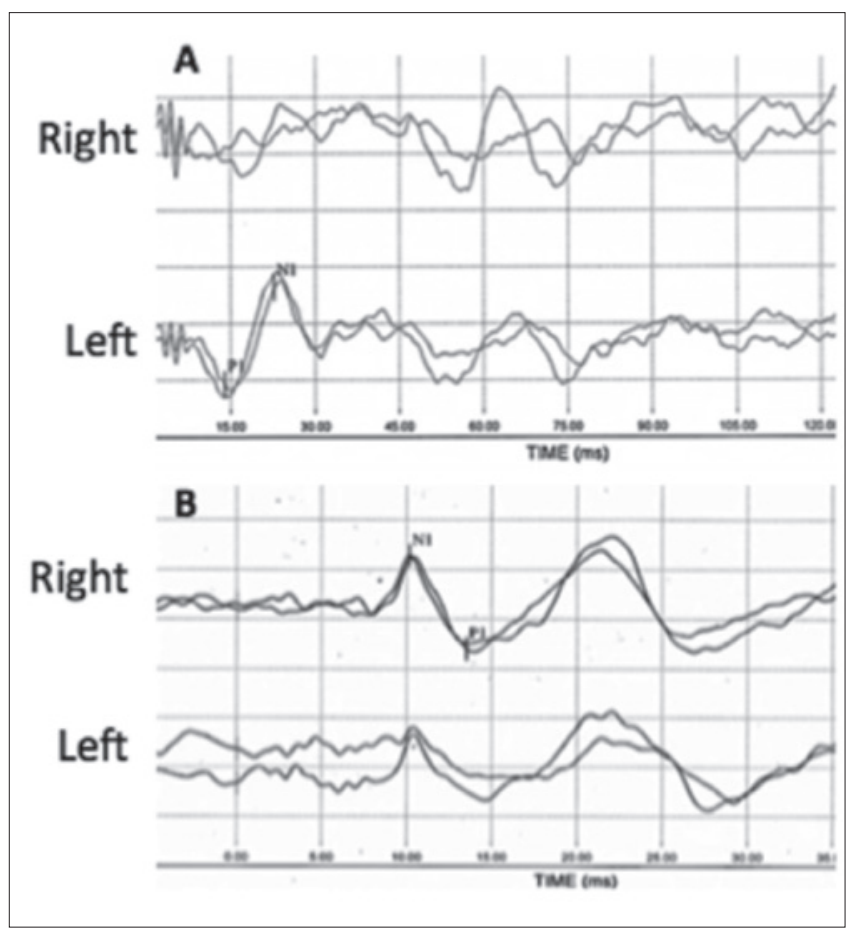

Fig. 2. Case 1, cervical vestibular evoked myogenic potentials (C-VEMPs) (A) and ocular vestibular evoked myogenic potentials (O-VEMPs) (B). C-VEMP are registered after air conducted $500 \mathrm{~Hz} \mathrm{~TB}$; the response is absent on the right side (uncrossed potential). Vestibular myogenic evoked potentials for otolithic function, 0-VEMPs, are registered after bone vibration $(500 \mathrm{~Hz})$ with a Bruel \& Kjaer minishaker at the hairline (Fz); the response is abnormal on the right side/ear (crossed potential). The first component of the 0-VEMP (n10) registered in the contralesional (left) eye is very small or absent and no reproducible, whereas the $n 10$ beneath the ipsilesional (right) eye is of normal amplitude.
In a second case we evaluated a 48-year-old woman that complained of brief episodes of spinning dizziness associated with head movements. Fourteen days prior she reported a long lasting spinning vertigo diagnosed as right UVL. Instrumental findings performed 5 weeks before were the following: complete $\mathrm{CP}$ on the right side and high frequency VOR gain studied with vHIT on the right side equal to $0.56,0.31$ and 0.31 for the $\mathrm{HC}, \mathrm{AC}$ and $\mathrm{PC}$, respectively (Fig. 3). C-VEMPs were absent on the right side and evocable on the left side (Fig. 4A); O-VEMPs showed no response only on the left side (same methodology illustrated above) (Fig. 4B). During the follow up visit we performed a bedside examination that revealed a left-beating head shaking and vibration-induced nystagmus, but no spontaneous nystagmus. The right Dix-Hallpike manoeuvre revealed a torsional (with anti-clockwise direction) up-beating nystagmus. Magnetic resonance imaging (MRI) brain scan, performed on both patients, showed no abnormalities. No audiological impairment and, in particular, no air-bone gap was detected. The examination revealed a PC-PPV affecting the same side of superior and inferior neurolabyrinthitis. Both patients underwent a successful therapeutic Semont's maneuver to treat the PC-PPV 9 .

\section{Discussion}

The combined use of new diagnostic tools like C-VEMP, O-VEMP and vHIT allows to assess impairment of the otolith organs and semicircular canals, and therefore to differentiate involvement of the vestibular receptor in UVL patients ${ }^{5-7}$. CVT and vHIT allow examining HC function with a low $(0.03 \mathrm{~Hz})$ and high $(5-7 \mathrm{~Hz})$ frequency range of the stimulus; in turn, both tests provide information about superior VN function. The most recent vHIT devices even allow testing of the AC and PC; a normal VOR gain on the $\mathrm{PC}$ suggests that the function of the inferior VN is preserved. Moreover, saccular and inferior VN function can be studied with C-VEMPs, and utricular and superior VN function with O-VEMPs. Despite the large number of studies that have attempted to clarify the proper pathway of O-VEMPs, these potentials reflect mainly utricular and superior VN function. Moreover, the efferent branch of the reflex seems to be independent with respect to the stimulus employed; however, bone conducted stimulus administered to the midline $\mathrm{Fz}$ is considered the most efficient ${ }^{10}{ }^{11}$. Both O-VEMPs and C-VEMPs have been employed to diagnose cases of UVL with selective involvement of the inferior $\mathrm{VN}^{12}$.

Although the aetiology has not yet been understood, BP$\mathrm{PV}$ is classified as idiopathic in most cases; however, its 


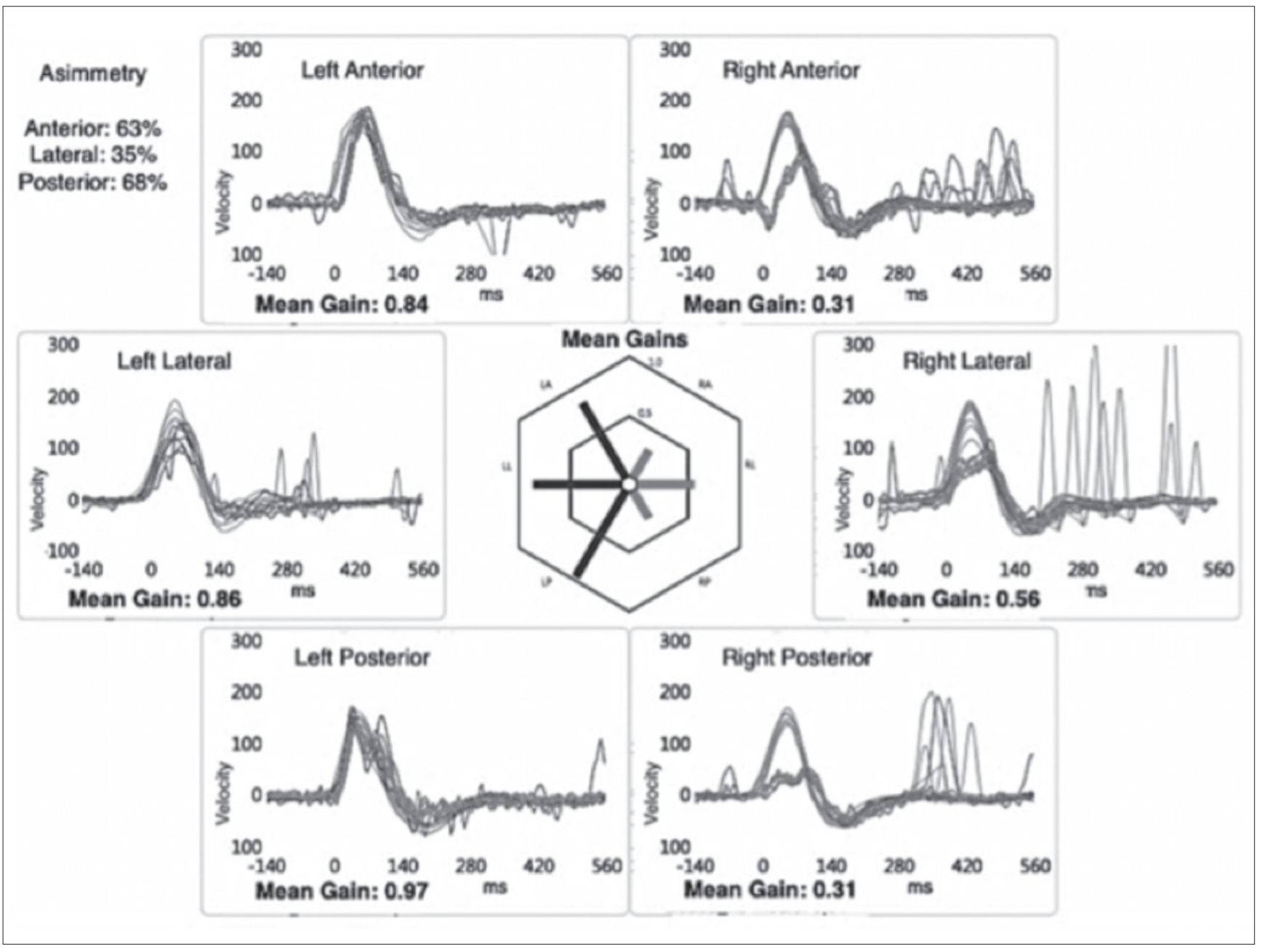

Fig. 3. Case 2, video head impulse test performed by employing a dedicated device ("ICS Impulse" system; GN Otometrics, http://www.ics-impulse.com). Right lateral canal, anterior canal and posterior canal gain are very low $(0.56,0.31,0.31$ respectively).

pathogenesis is almost certain and attributable to detachment and displacement of otoliths in one semicircular canal. Since the results of our vestibular tests indicated functional impairment of the structures innervated by the inferior VN (or of the inferior VN itself), it is hard to understand how a stimulus on the PC could reach vestibular nuclei and then oculomotor nuclei. Since normal MRI excluded a central origin of the positional nystagmus, some hypotheses can be formulated. PC loss of function can be caused by PPV itself: the literature shows that HC-PPV can affect the results of both CVT and HIT ${ }^{13}$; we did not consider this theory because our tests were performed before finding any sign of PPV. A simpler explanation is that sufficiently preserved function in the PC and inferior VN allows a severe PPV to manifest itself despite instrumental findings. Differently, if we assume that neurolabyrinthitis is caused by a loss of inputs from PC ampulla (pathological PC-VOR gain) and from the saccule (absent C-VEMPs), how can the PC-PPV be explained? We can hypothesise that a type 2 cell preservation in PC would be able to make the cupula respond to low-frequency stimuli such as free-floating otoconia, whereas the damaged type 1 cells would not allow the cupula to respond to high frequency stimuli like vHIT. A different theory implies the inferior $\mathrm{VN}$ fibres to be the site of the lesion: in this case, the intact PC ampulla receptors would respond to otoconia. However, it would be harder to explain how residual neural activity would make the $\mathrm{VN}$ reactive only to positioning manoeuvres (slow displacement of the cupula), but not to the vHIT. A role in this sense could be played by vestibulo-cochlear anastomoses first described by Von Oort in $1981^{14}$. This would explain the presence of PPV and the absence of C-VEMPs in case of complete VN impairment; however, it still implies a stimulus-dependent 


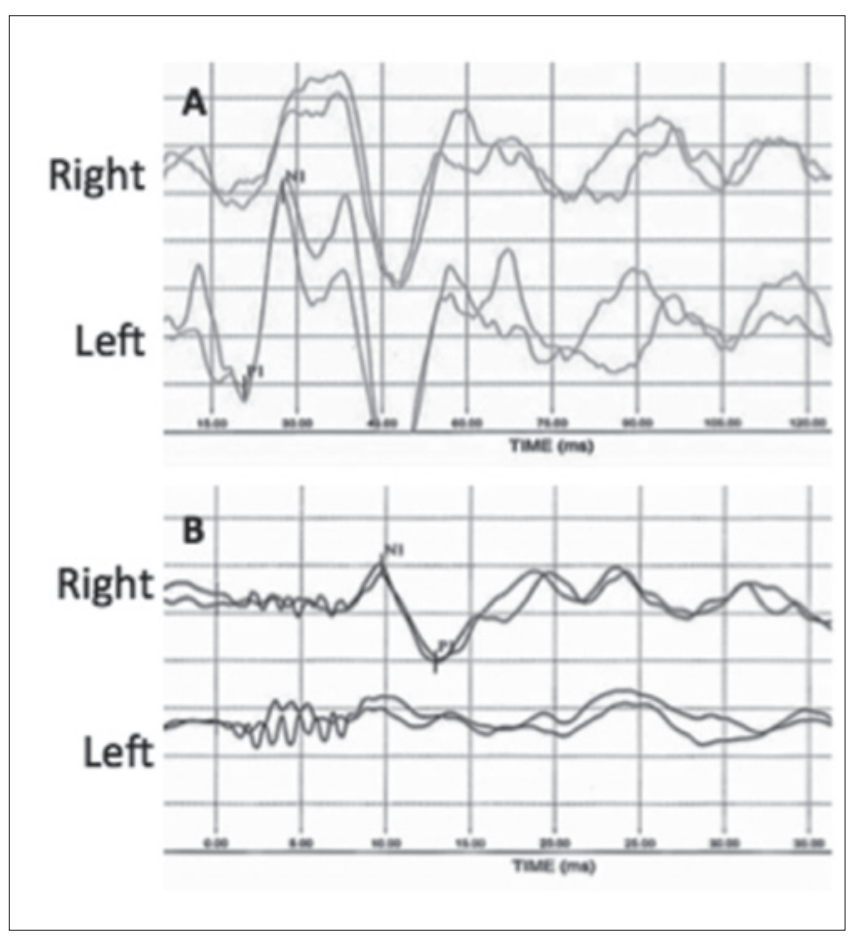

Fig. 4. Case 2, air conducted cervical vestibular evoked myogenic potentials (C-VEMPs) (A) and bone conducted ocular vestibular evoked myogenic potentials (0-VEMPS) (B). C-VEMP are registered after air conducted $500 \mathrm{~Hz}$ $\mathrm{TB}$; the response is absent on the right side (uncrossed potential). Vestibular myogenic evoked potentials for otolithic function, 0-VEMP, are registered after bone vibration $(500 \mathrm{~Hz})$ with a Bruel \& Kjaer minishaker at the hairline $(F z)$; the response is abnormal on the right side/ear (crossed potential). The first component of the 0-VEMP (n10) registered in the contralesional (left) eye is absent, whereas the $n 10$ beneath the ipsilesional (right) eye is of normal amplitude.

transmission of the afferent inputs by the anastomoses. One should also take in account that the amplitude of the potential is extremely dependent on sternocleidomastoid muscle contraction and on the age of the patient: sometimes the lack of reliability of C-VEMPs does not necessarily imply the presence of pathology ${ }^{15}$. It is also possible that our findings might be due to artefacts. However, the standardised methodology used and the presence of a reliable p1-n1 complex (with normal amplitude and latencies) on the healthy side make this possibility less plausible. Finally, because of the neural pathway of VEMPs, it is also possible that there are aspects that are still not completely understood.

\section{Conclusions}

The present cases show that a clinical entity attributable to Lindsay-Hemenway syndrome is possible even though vestibular instrumental assessment shows complete labyrinthine impairment. Therefore, even in this case, a diag- nosis of PPV should be considered and close follow-up is recommended. Some hypotheses about the findings can be made, even if further studies are needed for better comprehension.

\section{Acknowledgements}

The study was partially funded by "Fondazione Mario Marianelli".

\section{Conflict of interest statement}

None declared.

\section{References}

1 Lindsay J, Hemenway W. Postural vertigo due to unilateral sudden partial loss of vestibular function. Ann Otol Rhinol Laryngol 1956;65:692-706.

2 Schuknecht HF, Kitamura K. Second Louis H Clerk lecture. Vestibular neuritis. Ann Otol Rhinol Laryngol 1981;90:1-19.

3 Proctor L, Perlman H, Lindsay J, et al. Acute vestibular paralysis in herpes zoster oticus. Ann Otol Rhinol Laryngol 1979;88:303-10.

4 Büchele W, Brandt TH. Vestibular neuritis, a horizontal semicircular canal paresis? Adv Oto-Rhino-Laryngol 1988;42:157-61.

5 Curthoys IS. The interpretation of clinical tests of peripheral vestibular function. Laryngoscope 2012;122:1342-52.

6 Taylor RL, McGarvie LA, Reid N, et al. Vestibular neuritis affects both superior and inferior vestibular nerves. Neurology 2016;87:1704-12.

7 Magliulo G, Gagliardi S, Ciniglio Appiani M, et al. Vestibular neurolabyrinthitis: a follow-up study with cervical and ocular vestibular evoked myogenic potentials and the video head impulse test. Ann Otol Rhinol Laryngol 2014;123:162-73.

8 Murofushi T, Halmagyi GM, Yavor RA, et al. Absent vestibular evoked myogenic potentials in vestibular neurolabyrinthitis. An indicator of inferior vestibular nerve involvement? Arch Otolaryngol Head Neck Surg 1996;122:845-8.

9 Albera A, Boldreghini M, Canale A, et al. Vertigo returning to the sitting position after the Semont manoeuvre. Is it a prognostic symptom? Acta Otorhinolaryngol Ital 2018;38:145-150.

10 Rosengren SM, Kingma H. New perspectives on vestibular evoked myogenic potentials. Curr Opin Neurol 2013;26:74-80.

11 Curthoys IS, Iwasaki S, Chihara Y, et al. The ocular vestibular-evoked myogenic potential to air-conducted sound; probable superior vestibular nerve origin. Clin Neurophysiol 2011;122:611-6.

12 Manzari L, Burgess AM, Curthoys IS. Ocular and cervical vestibular evoked myogenic potentials in response to bone- 
conducted vibration in patients with probable inferior vestibular neuritis. J Laryngol Otol 2012;126:683-91.

13 Strupp M, Brandt T, Steddin S. Horizontal canal benign paroxysmal positioning vertigo: reversible ipsilateral caloric hypoexcitability caused by canalolithiasis? Neurology 1995;45:2072-6.
14 Oort H. Über die verästelung des nervus octavus bei Säugetieren. (Modell des utriculus und sacculus des kaninchens). Anat Anz 1918;51:272-80.

15 Welgampola MS, Colebatch JG. Vestibulocollic reflexes: normal values and the effect of age. Clin Neurophysiol 2001;112:1971-9.

Received: December 16, 2016 - Accepted: March 21, 2017

Address for correspondence: Augusto Pietro Casani, Department of Medical and Surgical Pathology, Otorhinolaryngology Section, Pisa University Hospital, via Paradisa 2, 56126 Pisa, Italy. Tel. +39 050 997496. Fax +39050 997542. E-mail: augusto.casani@unipi.it 